An Introduction to Chinese Art 
by the same autbor

次

CHINESE ART IN THE TWENTIETH CENTURY 



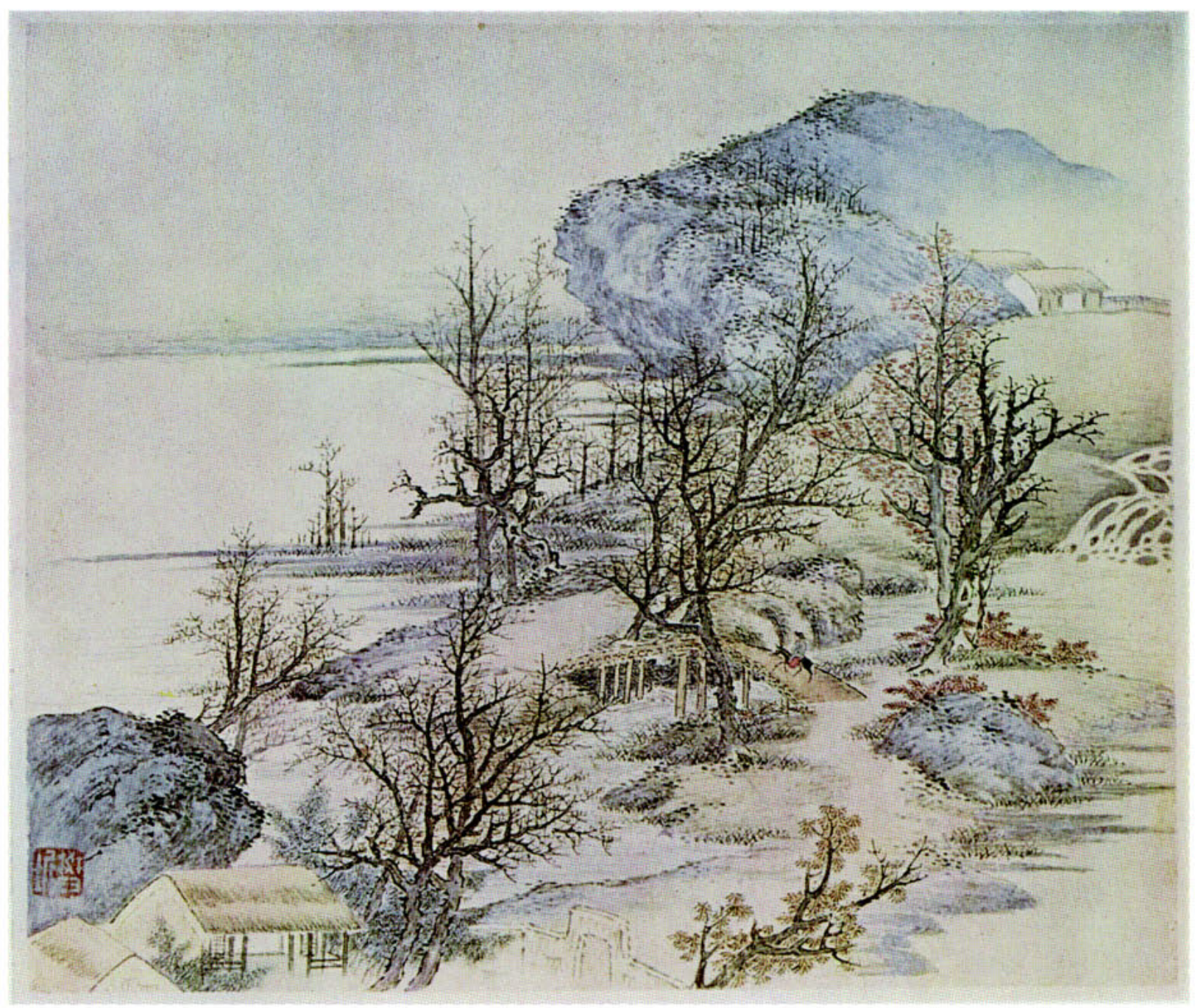

A. Fan Ch'i: Spring by the River.

Album painting on paper, dated 1646 . Ht. $15.3 \mathrm{~cm}$. Ch'ing Dynasty.

Mr. Richard Hobart. 


\section{AN INTRODUCTION $\mathrm{TO}$ \\ CHINESE ART \\ by \\ MICHAEL SULLIVAN}

UNIVERSITY OF CALIFORNIA PRESS

Berkeley and Los Angeles: 1961 
(C) 1960 by Michael Sullivan

University of California Press

Berkeley and Los Angeles, California

English Edition

Faber and Faber, Ltd., London

Printed in Great Britain 
KHOAN 
